\title{
Flow Related Aneurysm in Hemangioblastoma and Literature Review of Hemorrhagic Rate and Management Strategy
}

\author{
Choo Heng Tan, FRCS*, Felicia HZ Chua, MBBS, MRCS and Peter Y $K$ Hwang, FRACS \\ Department of Neurosurgery, National Neuroscience Institute, Singapore \\ *Corresponding author: Choo Heng Tan, Department of Neurosurgery, National Neuroscience Institute, \\ 11 JIn Tan Tock Seng, Level 1, 308433, Singapore
}

\begin{abstract}
Background: Hemangioblastoma is known to be a vascular tumor although its hemorrhagic rate is low. The association with aneurysm can be due to flow related in highly vascular pathology like hemangioblastoma or secondary to presence of hypoxic induced factor and vascular endothelial growth factor in case of Von-Hippel Lindau syndrome. However, the hemorrhagic rate and management strategy is not well established in patients with co-existence of hemangioblastoma and aneurysm.

Case report: This is a 60-years-old man who developed acute cerebellar hematoma with intraventricular extension. CT angiogram showed left cerebellar ring enhancing lesion with an aneurysm adjacent to it. It was a flow related aneurysm as the aneurysm aroused from the cortical branch of posterior inferior cerebellar artery which was also a feeder to the hemangioblastoma. He underwent posterior fossa craniectomy, excision of left cerebellar hemangioblastoma and clipping of the flow related aneurysm in view of neurological deterioration. The reason of clipping the aneurysm was to avoid rebleeding from ruptured aneurysm or possibly normal pressure perfusion breakthrough. Patient recovered well eventually with mild cerebellar signs.

Conclusion: We would recommend to consider doing angiogram (CT or MR) as a screening for possible flow or nonflow related aneurysm. This would certainly assist in surgical planning and possible endovascular treatment prior to excision of hemangioblastoma.
\end{abstract}

\section{Keywords}

Flow related aneurysm, Hemangioblastoma, Hemorrhagic rate, Angiogram, Clipping, Endovascular treatment

\section{Abbreviations}

CT: Computerized Tomography; ELST: Endolymphatic Sac Tumor; GCS: Glasgow Coma Scale; HIF: Hypoxic Induced Factor; IVH: Intraventricular Hematoma; MR: Magnetic Resonance; PICA: Posterior Inferior Cerebellar Artery; VEGF: Vascular Endothelial Growth Factor; VHL: Von Hippel Lindau

\section{Introduction}

Hemangioblastoma is known to be a highly vascular tumor, however its spontaneous hemorrhagic rate was reported to be low [1]. Other rare causes of spontaneous hemorrhage on top of tumoral bleed in patient with hemangioblastoma include bleeding from aneurysm whether it is flow related or not. Patients with hemangioblastoma with flow related aneurysm noted in CT or MR angiogram could have higher incidence of hemorrhage. We are reporting a case of infratentorial hemangioblastoma with hemorrhage possibly from the flow related aneurysm.

\section{Case Report}

This is a 60-years-old man who developed sudden onset headache and giddiness during his sexual intercourse. He was brought to our hospital with GCS of E2V2M5 on arrival. CT brain was performed and it showed a left cerebellar hematoma with extension into forth ventricle and gross intraventricular hematoma (IVH) as shown in Figure 1. CT angiogram showed a contrast enhancing cystic mass at left cerebellar hemisphere with aneurysm arising from left cortical segment of posterior inferior cerebellar artery (PICA) as shown in Figure 2.

External ventricular drain was inserted initially with expected GCS improved to E3V3M6. CT thorax, abdomen and pelvis were performed and no feature of primary malignancy was noted. Otherwise, he also had no other clinical or radiological features of Von Hippel Lindau syndrome.

He had a neurological deterioration secondary to

Citation: Tan CH, Chua FHZ, Hwang PYK (2021) Flow Related Aneurysm in Hemangioblastoma and Literature Review of Hemorrhagic Rate and Management Strategy. Neurosurg Cases Rev 4:068. doi. org/10.23937/2643-4474/1710068

Accepted: May 27, 2021; Published: May 29, 2021

Copyright: (C) $2021 \mathrm{Tan} \mathrm{CH}$, et al. This is an open-access article distributed under the terms of the Creative Commons Attribution License, which permits unrestricted use, distribution, and reproduction in any medium, provided the original author and source are credited. 


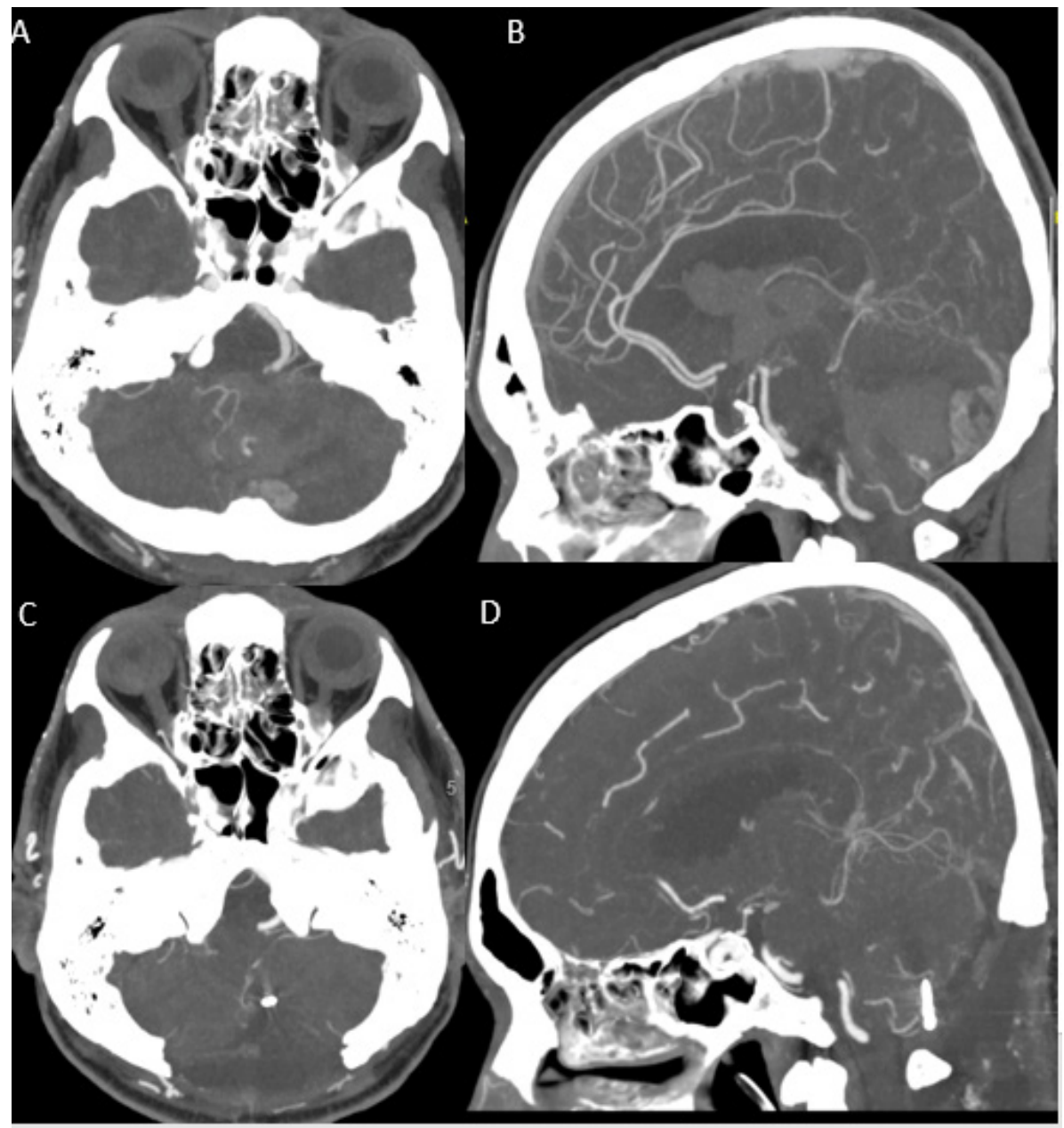

Figure 1: CT angiogram ( $A$ and $B$ ) Showed left cerebellar ring enhancing cystic lesion with PICA feeder. A flow related aneurysm is noted from cortical branch of left PICA; (C) Subsequent post-op scan showed aneurysm clipped on axial; (D) Sagittal view.

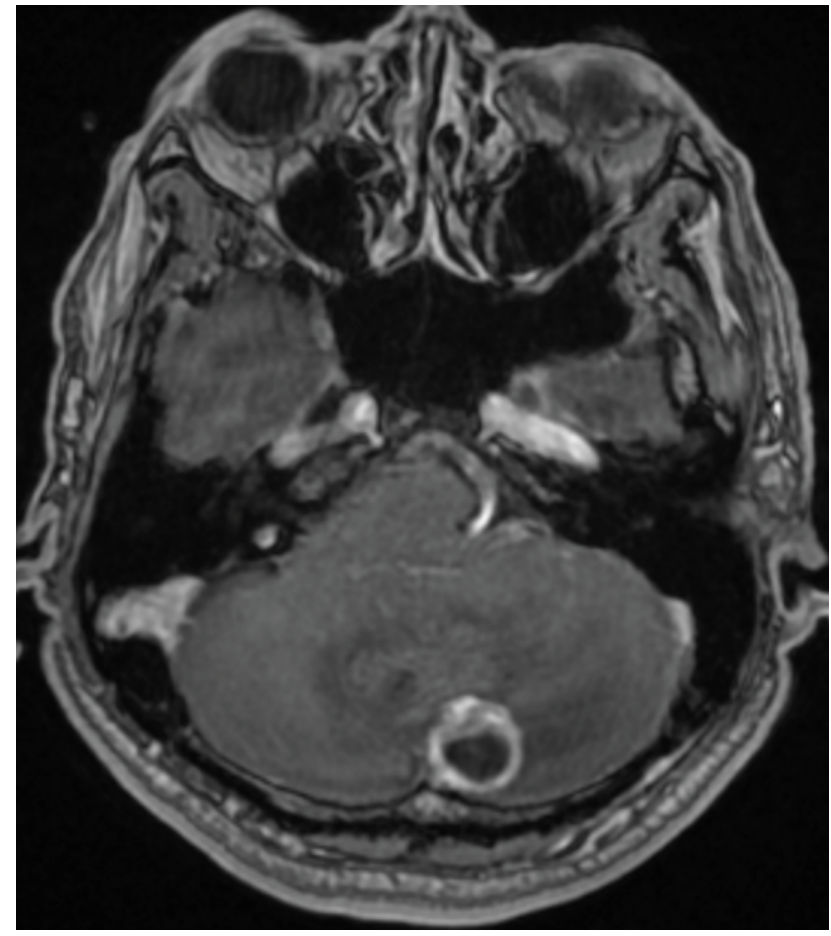

Figure 2: Pre-operative MRI brain with contrast which showed ring enhancing left cerebellar cystic lesion with mural nodule which is typical of hemangioblastoma. signs of brainstem compression. Therefore, posterior fossa craniectomy was performed, followed by excision of left cerebellar hemangioblastoma and evacuation of cerebellar hematoma. Intraoperatively, left cortical segment of PICA was explored and multi-lobulated aneurysm was clipped. Patient recovered uneventful with mild cerebellar signs.

\section{Discussion}

Hemangioblastoma was previously known as "Lindau's tumour" [2] it is a relatively common vascular central nervous system (CNS) lesion. Sixty-two percent of cases are sporadic and $38 \%$ manifestedas Von Hippel Lindau syndrome [3] which was previously known as Lindau's disease. Diagnoses of VHL were initially established based on the criteria Melmon and Rosen [2] described, which was defined as presence of cerebellar hemangioblastoma in presence of one of the Lindau's complex (retinal hemangioblastoma, pancreatic cyst, renal or epididymal abnormalities). Melmon and Rosen, et al. [2] further proposed to enlarge the diagnosis of Lindau's disease to include patients with only a single lesion of Lindau Complex, provided documentation of a central nervous system hemangioblastoma exists in 
Table 1: Reported hemangioblastoma cases with or without flow-related aneurysm.

\begin{tabular}{|c|c|c|c|c|c|}
\hline Authors, Year & VHL & $\begin{array}{l}\text { Location of } \\
\text { Hemangioblastoma }\end{array}$ & $\begin{array}{l}\text { Flow related } \\
\text { aneurysm }\end{array}$ & Bleeding & Management \\
\hline Present & No & Cerebellum & Yes & Yes & Resection and Clipping \\
\hline Hai Qian, et al. 2019 [12] & No & Cerebellum & Yes & No & Resection and Clipping \\
\hline Zhou, et al. 2018 [13] & Yes & Cerebellum & No & No & Resection \\
\hline Lu, et al. 2016 [14] & Yes & Cerebellum & Yes & No & Conservative \\
\hline Surico, et al. 2015 [15] & No & Cerebellum & No & Yes & $\begin{array}{l}\text { Endovascular } \\
\text { (Hemangioblastoma and } \\
\text { Aneurysm) }\end{array}$ \\
\hline \multirow[t]{2}{*}{ Raygor, et al. 2014 [10] } & \multirow[t]{2}{*}{ Unknown } & \multirow{2}{*}{$\begin{array}{l}\text { Medullary-cervical } \\
\text { junction }\end{array}$} & \multirow[t]{2}{*}{ Yes } & \multirow[t]{2}{*}{ Yes } & Resection and Clipping \\
\hline & & & & & (Failed endovascular) \\
\hline Suzuki, et al. 2014 [16] & Unknown & Cerebellum & Yes & Yes & $\begin{array}{l}\text { Endovascular and } \\
\text { Resection }\end{array}$ \\
\hline $\begin{array}{l}\text { Seong Eom, et al. } 2011 \\
\text { [11] }\end{array}$ & No & Cerebellum & Yes & No & $\begin{array}{l}\text { Endovascular and } \\
\text { Resection }\end{array}$ \\
\hline Sharma, et al. 2006 [6] & Yes & Cerebellum & No & No & $\begin{array}{l}\text { Resection of } \\
\text { hemangioblastoma (SAH } \\
\text { bleed was } 6 \text { years ago) }\end{array}$ \\
\hline Murai, et al. 2006 [17] & No & Cerebellum & No & No & Resection \\
\hline Zager, et al. 2002 [18] & Yes & Cerebellum & Yes & No & $\begin{array}{l}\text { Resection and Clipping/ } \\
\text { Trapping of aneurysm }\end{array}$ \\
\hline Menovsky, et al. 2002 [8] & No & Cerebellum & Yes & $\begin{array}{l}\text { Yes (5 years } \\
\text { after aneurysm } \\
\text { wrapping } \\
\text { and tumour } \\
\text { resection) }\end{array}$ & $\begin{array}{l}\text { Resection and Wrapping } \\
\text { of aneurysm (subsequent } \\
\text { SAH was not treated) }\end{array}$ \\
\hline $\begin{array}{l}\text { Guzman and Grady, et } \\
\text { al.1999 [19] }\end{array}$ & No & Cerebellum & Yes & Yes & Resection and Clipping \\
\hline Ueno, et al. 1977 [20] & No & Cerebellum & No & No & Unknown \\
\hline Yoshii, et al. 1976 [21] & Yes & Cerebellum & No & Yes & Resection \\
\hline
\end{tabular}

at least other family member. Frequency of CNS lesions associated with $\mathrm{VHL}$ in descending order include cerebellar hemangioblastoma, retinal hemangioblastoma, spinal hemangioblastoma, brainstem hemangioblastoma, endolymphatic sac tumor (ELST) and supratentorial hemangioblastoma [4]. Of note, bilateral ELSTs are pathognomonic of VHL [5].

However, the association with cerebral aneurysm with hemangioblastoma remains rare with only 15 cases reported. Nine cases were reported to have a flow related aneurysm. The possible pathophysiology behind the association is secondary to upregulation of type 1-Matrix Metalloproteinase leading to accelerated enzymatic degradation of the extracellular matrix [6]. With mutation of VHL gene and presence of hypoxia induced factor (HIF), the enhanced expression of vascular endothelial growth factor (VEGF) serves as an angiogenesis factor in aneurysm formation [7]. Flow related aneurysms were previously reported as well in association with hemangioblastoma regardless of its association with VHL. This is likely secondary to increased arterial flow to hemangioblastoma [8].

Spontaneous hemorrhagic risk of CNS hemangioblastoma was noted to be as low as 0.0024 per person

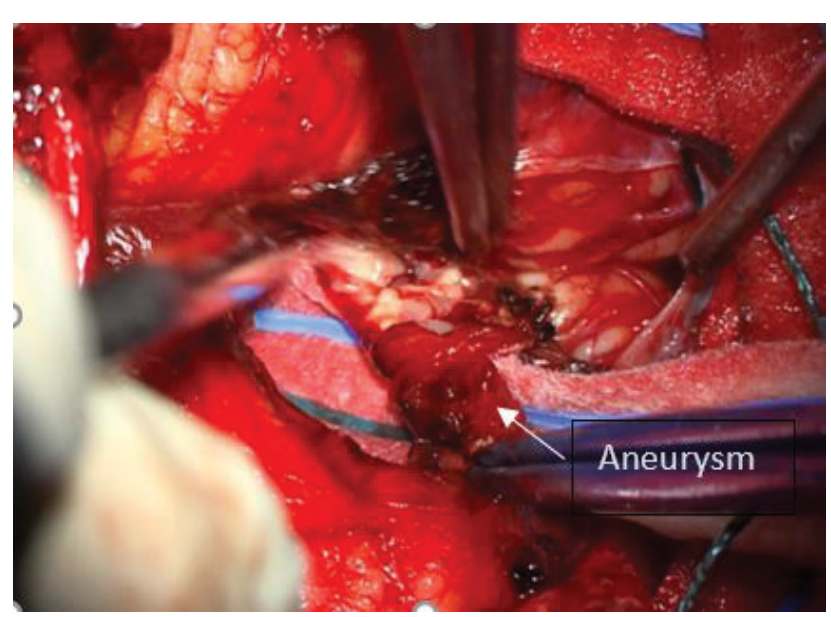

Figure 3: Flow related distal PICA aneurysm.

per year [1]. The average size of the lesion with association with hemorrhage was $2.3 \mathrm{~cm}$ in the literature review. Hemorrhage could be in the form of parenchymal bleed or subarachnoid bleed, and it was also reported that isolated intraventricular bleed is exceptional [9]. Cervical hemangioblastoma is also a known cause of intracranial subarachnoid hemorrhage apart from brainstem hemangioblastoma or associated aneurysm bleed 
[9]. Early post-operative hemorrhage from excision of hemangioblastoma could be secondary to a similar mechanism from arteriovenous malformation surgery, known as normal perfusion pressure breakthrough [1]. This is because of the loss of normal autoregulatory response and remains vasodilated post-surgical excision.

According to Table $1[6,8,10-21]$ five out of nine cases with flow related aneurysm had a hemorrhage. Therefore, the estimated bleeding rate with flow related aneurysm is approximately $56 \%$. Two out of six cases with non-flow related aneurysm suffered subarachnoid hemorrhage. Overall, the flow related aneurysm appears to be associated with higher risk of hemorrhage as compared to patients with non-flow related aneurysm. Cause of hemorrhage in our case is more likely to be secondary to flow related aneurysm and less likely to be hemangioblastoma in view of lower hemorrhagic risk from tumor itself. There were 2 reported cases of aneurysm embedded within the tumor capsule $[10,11]$. Five reported cases were confirmed to have VHL syndrome, and two of them had flow related aneurysm although none of the flow related aneurysm bleed.

Endovascular treatment is known to be an option of treatment as sole or adjunctive treatment of hemangioblastoma. However, endovascular treatment may be limited for cerebellar cases as compared to spinal cord cases as it is associated with higher rate of post-embolization hemorrhage $[22,23]$. This phenomenon is postulated to be secondary to migrating small particles which could lead to capillary hypertension [22]. Furthermore, pre-operative embolization of hemangioblastoma did not show a superior gross total resection of the tumor or lesser estimated blood loss or complication according to systemic review done by Ampie, et al. [24]. Thus, Cornelius, et al. advised embolization of hemangioblastoma using glue materials if it has to be performed. In this case, we proceeded with surgery with 3 surgical goals which were decompression of brainstem, surgical resection of hemangioblastoma and clipping of flow related PICA aneurysm. The patient recovered well with no post-operative complication.

We advocate consideration of $\mathrm{CT}$ angiogram or MR angiogram as a form of screening tool for patient with hemangioblastoma, and pre-operative planning should not be taken lightly. Digital subtraction angiogram should be considered as an important adjunct if flow related aneurysm is detected on top of the hemangioblastoma. Non flow related aneurysm would need to be monitored closely with option of upfront or interval treatment. Flow related aneurysm should be clipped or embolized either prior or during the surgical excision of hemangioblastoma in view of higher inherent risk of aneurysm bleed. Having said that, true incidence of aneurysm and natural history of flow related aneurysm could not be ascertained without routine pre-operative angiogram.

\section{Declarations of Interest}

The authors declare no conflicts of interest.

\section{Funding}

No funding was needed for the production of this manuscript.

\section{References}

1. Glasker S, Velthoven VV (2005) Risk of hemorrhage in hemangioblastomas of the central nervous system. Neurosurgery $57:$ 71-76.

2. Melmon KL, Rosen SW (1964) lindau's disease. Review of the literature and study of a large kindred. Am J Med 36: 595-617.

3. Conway JE, Chou D, Clatterbuck RE, Brem H, Long DM, et al. (2001) Hemangioblastomas of the central nervous system in von Hippel-Lindau syndrome and sporadic disease. Neurosurgery 48: 55-62.

4. Chittiboina P, Lonser RR (2015) Von Hippel-Lindau disease. Handb Clin Neurol 132: 139-156.

5. Lonser RR, Baggenstos M, Kim HJ, Butman JA, Vortmeyer AO (2008) The vestibular aqueduct: Site of origin of endolymphatic sac tumors. J Neurosurg 108: 751-756.

6. Sharma MS, Jha AN (2006) Ruptured intracranial aneurysm associated with von Hippel-Lindau syndrome: a molecular link? J Neurosurg 104: 90-93.

7. Skirgaudas M, Awad IA, Kim J, Rothbart D, Criscuolo G (1996) Expression of angiogenesis factors and selected vascular wall matrix proteins in intracranial saccular aneurysms. Neurosurgery 39: 537-545.

8. Menovsky T, Andre Grotenhuis J, Bartels RH (2002) Aneurysm of the anterior inferior cerebellar artery (AICA) associated with high-flow lesion: Report of two cases and review of literature. J Clin Neurosci 9: 207-211.

9. de San Pedro JR, Rodriguez FA, Niguez BF, Sanchez JF, Lopez-Guerrero AL, et al. (2010) Massive hemorrhage in hemangioblastomas literature review. Neurosurg Rev 33: 11-26.

10. Raygor KP, Rowland NC, Cooke DL, Solomon DA, Huang MC (2014) Aneurysm of the posterior meningeal artery embedded within a dorsal exophytic medullary hemangioblastoma: Surgical management and review of literature. J Cerebrovasc Endovasc Neurosurg 16: 293-298.

11. Seong Eom K, Won Kim D, Sung Choi S, Ha Choi K, Young Kim T (2011) Preoperative embolization of a cerebellar haemangioblastoma using Onyx: Case report and literature review. Neurol Neurochir Pol 45: 292-296.

12. Qian H, Shi X, Wang L (2019) Distal outflow-related anterior inferior cerebellar artery aneurysm in hemangioblastoma. World Neurosurg 127: 284-288.

13. Zhou H, Sun S, Shi H, Ma K (2018) Cavernous sinus aneurysm associated with cerebellar hemangioblastoma in an adult with von hippel-lindau disease. J Craniofac Surg 29: e502-e506.

14. Lu J, Quan Y, Xu G, Gong SP (2016) Coexistence of intracranial aneurysm and hemangioblastoma: A case report and literature review. Neurochirurgie 62: 229-231.

15. Surico D, Amadori R, Garofalo G, Nuzzi NP, Carriero A, et al. (2015) "One-shot" endovascular management of cerebral aneurysm and fourth ventricle hemangioblastoma in a pregnant woman. Int J Gynaecol Obstet 129: 79-80. 
16. Suzuki M, Umeoka K, Kominami S, Morita A (2014) Successful treatment of a ruptured flow-related aneurysm in a patient with hemangioblastoma: Case report and review of literature. Surg Neurol Int 5: S430-S433.

17. Murai Y, Kobayashi S, Tateyama K, Teramoto A (2006) Persistent primitive trigeminal artery aneurysm associated with cerebellar hemangioblastoma. Case report. Neurol Med Chir (Tokyo) 46: 143-146.

18. Zager EL, Shaver EG, Hurst RW, Flamm ES (2002) Distal anterior inferior cerebellar artery aneurysms. Report of four cases. J Neurosurg 97: 692-696.

19. Guzman R, Grady MS (1999) An intracranial aneurysm on the feeding artery of a cerebellar hemangioblastoma. Case report. J Neurosurg 91: 136-138.

20. Ueno K, Mabuchi S, Echizenya K, Isu T, Goto S (1977)
[Incidentally-discovered aneurysm--a report of eight cases (author's transl)]. No Shinkei Geka 5: 183-188.

21. Yoshii Y, Maki Y, Tomono Y, Nakamura T (1976) [Cerebellar hemangioblastoma with multiple aneurysms]. No To Shinkei 28: 703-708.

22. Cornelius JF, Saint-Maurice JP, Bresson D, George B, Houdart E (2007) Hemorrhage after particle embolization of hemangioblastomas: comparison of outcomes in spinal and cerebellar lesions. J Neurosurg 106: 994-998.

23. Montano N, Doglietto F, Pedicelli A, Albanese A, Lauretti L, et al. (2008) Embolization of hemangioblastomas. J Neurosurg 108: 1063-1064.

24. Ampie L, Choy W, Lamano JB, Kesavabhotla K, Kaur R, et al. (2016) Safety and outcomes of preoperative embolization of intracranial hemangioblastomas: A systematic review. Clin Neurol Neurosurg 150: 143-151. 